\section{Higher Education in Taiwan: The Rule of Law and Democracy}

\author{
Wing-Wah Law \\ Wing-Wah Law is a lecturer in the School of Education at the University \\ of Hong Kong. Address: Pokfulam Rd., Hong Kong.
}

$\mathrm{H}$ igher education in Taiwan between the 1980s and 1990s provides an example of how the function of the law changed from restricting to protecting the freedom of tertiary institutions to govern themselves. Until the late 1980s, the Taiwanese lived under a totalitarian regime, and higher education was under rigid government control. The state controlled the establishment, administration, personnel, finance, and curriculum of all tertiary institutions. University presidents or academics could be easily dismissed without reasonable cause. Academic publications were assessed and screened by the Ministry of Education. Students were forced to take political ideology courses that transmitted the doctrines and ideas of Sun Yatsen (founder of the Republic of China in 1911) and his successors. Now Taiwan is a newly emerging democratic state. Universities and colleges have been given more power to manage themselves. Laws governing higher education were revised or promulgated to consolidate institutional and academic freedoms.

Since the lifting of martial law in 1987, Taiwan's higher education system has experienced a dramatic expansion.

\section{Growth and Diversity}

Since the lifting of martial law in 1987, Taiwan's higher education system has experienced a dramatic expansion. Between 1987 and 1997, the number of universities and colleges increased from 28 to 67 , and student enrollments rose from less than 200,000 to over 380,000. Whereas formerly, students were selected on the basis of their academic performance on joint college entrance examinations, the process has now been opened up to include four additional channels: (1) recommendation by school and selection by the university, (2) special admissions for the talented, (3) independent university recruitment, and (4) direct application of students for admissions. Tertiary institutions are now able to play an active role in the selection of students, and the selection criteria include factors such as leadership and extracurricular activities in secondary schools.
The New Legal Framework

As a response to the political democratization on the island, the state institutionalized the rule of law with regard to university autonomy. In the 1990s, three major laws (the University Law, Teacher Law, and Private Education Law) were revised or promulgated to adjust the relations between higher education's key players - the Ministry of Education, university administrators, and faculty. The revised University Law grants tertiary institutions autonomy over finance, personnel, and curriculum. The other two laws enhance the power of teachers, individuals, and the community, over higher education affairs.

\section{One of the mechanisms introduced to diversify the control of higher education is related to the enhancement of faculty power at various levels.}

\section{Enhancing Faculty Power}

One of the mechanisms introduced to diversify the control of higher education is related to the enhancement of faculty power at various levels. At the institutional level, faculty at public and private tertiary institutions are allowed to elect two or three candidates for university president and for deanships and to refer these names for final selection and appointment to the Ministry of Education and university presidents. Despite the fact that final control over appointments lies with the highest authorities, the election exercise has broadened the legitimacy of university leadership. Previously, the selection, appointment, and dismissal of university presidents at public and private tertiary institutions was controlled by the Ministry of Education and sponsoring bodies.

In order to be elected, would-be candidates for university president and deanships are required to campaign on the basis of their vision and performance, and to answer questions raised by faculty and students. Moreover, the state government has granted faculty members the power to negotiate as a body with university authorities. In accordance with the new University Law, tertiary institutions have established their own university faculty councils to deal with the recruitment, promotion, and dismissal of teachers.

\section{Accreditation}

The self-accreditation system of universities and colleges was introduced as the second type of mechanism to protect institutional autonomy in the 1990s. Formerly the 
Ministry of Education held absolute power to assess faculty qualifications and publications in matters of recruitment and promotion. The system also served as a tool of the state to reject academics and censor research or publications deemed inappropriate by the leadership of the ruling party. From 1991, the ministry gradually devolved the power of self-accreditation upon universities and colleges. By 1996-97, 15 universities had been granted such power.

In order to gain full self-accreditation status, tertiary institutions must pass through three stages. In the preparation stage, tertiary institutions must satisfy the minimum levels set by the ministry for passing rates for faculty publications in the preceding four years (70 percent for institutions with over 50 teachers who have submitted their publications for evaluation, and 90 percent for those with fewer than 20 teachers submitting publications). In the second stage, the ministry sends inspection teams to review the self-assessment processes of those universities that meet the minimum criteria. In particular, the teams check to see whether university faculty councils have been set up and are functioning properly. If institutions pass the on-site inspections, they proceed to the third stage-a three-year confirmation period, during which they are temporarily granted the power of self-assessment. At the end of this period, they are again reviewed. If they pass, full selfaccreditation status is granted. Nevertheless, qualified universities and colleges are still required to send the results of their self-assessments to the ministry for filing, while the others are required to continue submitting their publications for assessment.

\section{In order to gain full self-accreditation status, tertiary institutions must pass through three stages.}

\section{Decentralizing Curriculum Decisions}

The third type of mechanism introduced to protect university autonomy was the lifting of controls over "forbidden" disciplines that were formerly banned or exclusively offered by public tertiary institutions. These disciplines included religious education, teacher education, art education, and sports education-which were seen by the ruling party as possible threats to its leadership and the country's centrally prescribed value system. Religious education had been one such forbidden area. Private universities sponsored by religious bodies-such as Fu Jen Catholic University and Chung Yuan Christian University-were not allowed to offer a religious curriculum or establish divinity schools. In 1997, the Private Education Law was revised to permit individuals, private entities, and the community to establish educational institutions of every type except for military and police academies.

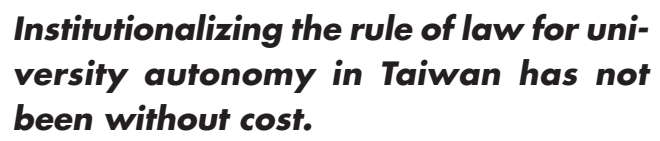

The revised Private Education Law also provided for a broader range of teacher education institutions. Formerly, training for primary and secondary school teachers could be offered only in publicly funded teacher training institutions-three normal universities and nine teacher colleges. This monopoly was broken after the enactment of the Teacher Training Act in 1994. Since then, nonnormal education institutions have been allowed to offer teacher training programs. In 1995-96, a total of 2,190 places were given, on a trial basis, to 22 nonnormal universities and colleges, including Tsinghua University and Taiwan Institute of Technology. After review, 7 public universities and 3 private universities were approved by the Ministry of Education to offer postgraduate courses for preservice teachers, starting in 1997-98.

\section{The Cost of Enhancing University Autonomy}

Institutionalizing the rule of law for university autonomy in Taiwan has not been without cost. Increasing the legitimacy of the university administration through election processes created opportunities for open conflicts between candidates and between their supporters over nonacademic issues. The opening up of teacher education intensified the competition between normal and nonnormal educational institutions for students. To prevent the loss of students to nonnormal universities and a drop in quality, normal universities and colleges requested that the Ministry of Education help them increase their competitiveness through status upgrades or restructuring.

More importantly, the institutionalization of university autonomy was a learning process for both the ministry and tertiary institutions. At first, university administrators and faculty hesitated to exercise their legal rights to guard against any infringement of university autonomy by the ministry. They nearly failed to do so over the issue of compulsory subjects. At a national conference for university presidents in 1995, the participants decided to retain as compulsory courses in Chinese language, foreign language, 
history, and particularly political ideology for all universities and colleges. Fortunately, that decision was challenged several months later by the Grand Justice Council, which ruled that the imposition of compulsory subjects in higher education violated both the constitution and the University Law and demanded the practice of imposing subjects be abolished. Under this judicial pressure, university presidents and the ministry finally agreed that tertiary institutions would be encouraged, rather than compelled, to incorporate such courses into their curricula. As a result, many universities made the political courses optional.

\section{Lawmakers also needed to learn to honor university autonomy}

Lawmakers also needed to learn to honor university autonomy - as with the issue of medium of instruction. The official medium of communication in public arenas including the classroom has been Mandarin, which is the spoken language of a minority of people (less than 15 percent of the population) who moved together with the Kuomintang to Taiwan. The language policy has suppressed the use of local dialects, Minnanese and Fujianese, spoken by a majority of people (over 85 percent). In the late 1990s, the repressive language policy was challenged by a number of institutions - such as Taiwan University and Chung Hsing University - that allowed their professors to teach in local dialects. This issue was later debated in the Education Commission of the Legislative Yuan (the counterpart of a parliament in Western countries). The legislators argued that the use of local dialects violated both the constitution and the rights of students who do not know these dialects. They also insisted that the Ministry of Education could not use university autonomy as an excuse to abdicate its supervisory duty. In the end, the minister of education refused to interfere with the language policy in these universities, despite his reassertion that Mandarin is the official medium of communication.

\section{Conclusion}

The rule of law for democracy in Taiwan in the 1990s was not only a necessary condition, but also a catalyst for the protection and enhancement of academic freedom. Despite a lack of a tradition of university autonomy, mechanisms were created to make manifest the rule of law for democracy so as to reduce the possibility of the domination of higher education by the state. In the newly democratic Taiwan, the state, academics, politicians, and the community are in the process of learning how to exercise and honor university autonomy.

\section{The Cost of Higher Education to Students and Parents in Rus- sia: Tuition Policy Issues}

\section{Olga Bain}

Olga Bain is a doctoral candidate in higher and comparative education at the State University of New York at Buffalo. Address: 468 Baldy Hall, SUNY at Buffalo, Buffalo, NY 14260, USA.

$\mathrm{T}$ here is a worldwide trend in higher education toward privatized financing. Against a background of declining public resources, students and their parents are increasingly expected to assume a larger share of the cost of higher education. Among recent backers of fee-paying higher education are those countries undergoing the transformation from a planned to a market economy.

According to the 1993 constitution, citizens of the Russian Federation are entitled to tuition-free higher education. Drawing on the Soviet model, the constitution stresses such social values as equality of access, social mobility, and meritocracy. Developments in Russian higher education today are increasingly shaped by financial pressures. Severe shortages of public monies make the former practice of full public support for higher education not only undesirable but impossible. The issues of charging tuition fees and distributing the costs of education among multiple parties-private and public employers, local governments, and students themselves-have been placed on the policy agenda. As early as 1992, the Law on Education introduced the concept of higher education cost sharing that was complemented by a loan plan similar to the one in use in the United States. Since that time, however, tuition and loan-scheme proposals have alternately moved in and out of policy discussions.

\section{The Law on Education introduced the con- cept of higher education cost sharing that was complemented by a loan plan simi- lar to the one in use in the United States.}

With an eye to urging more efficient use of resources and more responsive behavior among education providers, proposals for indirectly rather than directly allocating taxpayer funds to Russian higher education institutions were introduced as early as the mid-1980s. Contract training - a targeted training of graduates for particular public industries and enterprises - was intended to bring additional resources to education. But this was a quasi-tuition model and had little effect on institutional behavior, as the costs of training were 